\title{
Elogio, mecenazgo y profesionalización del teatro de la segunda mitad del siglo XVII: la loa en la órbita entremesil*
}

\author{
JUDITH FARRÉ VIDAL \\ Centro de Ciencias Humanas y Sociales, CSIC, Madrid
}

Para Josep Maria Sala Valldaura, maestro espléndido.

La primera reflexión de conjunto sobre la loa como género teatral se debe a Joseph A. Meredith, que en 1908 publicaba Introito and loa in the Spanish Drama of the Sixteenth Century, ${ }^{1}$ un estudio en el que trazaba un recorrido histórico del género, desde sus orígenes hasta las loas del Viaje entretenido de Agustín Rojas Villandrando, cuando éstas ya aparecían desligadas argumentalmente de la pieza principal. Posteriormente, Jean Louis Fleckniakoska sacó a la luz la segunda monografía sobre esta forma dramática: La loa (1975). ${ }^{2}$ Su propósito es el estudio de la loa desde 'los orígenes conocidos del teatro español hasta fines de la primera mitad del siglo XVII' ${ }^{3}$ A partir de la distinción de tres tipos formales de loas: entremesada, dialogada y monológica, su interés se centra en el análisis del monólogo recitado, por lo que el investigador considera que las loas de la Jocosería de Quiñones de Benavente (1645) son el punto de inflexión para trazar la

* Este trabajo se inscribe en el marco del programa Ramón y Cajal en la convocatoria 2008 ('Técnicas dramáticas de composición del teatro breve de los Siglos de Oro desde una perspectiva comparada', RYC-2008-02362) y del proyecto Edición y estudio del teatro breve de Antonio de Solís, financiado por la Subdirección General de Investigación, Desarrollo e Innovación del Ministerio de Economía y Competitividad (FFI-2011-25118). También cuenta con el patrocinio de TC-12, en el marco del Programa Consolider-Ingenio 2010, del Plan Nacional de Investigación Científica, Desarrollo e Innovación Tecnológica (SD2009-00033).

1 Joseph A. Meredith, Introito and loa in the Spanish Drama of the Sixteenth Century (Philadelphia: Univ. of Pennsylvania Press, 1908).

2 Jean-Louis Flecniakoska, La loa (Madrid: Sociedad General Española de Librería, 1975).

3 Flecniakoska, La loa, 11. 
morfología del género, ya que a partir de este momento 'la loa viene a ser como un entremés, con varias figuras, presentado en su propio decorado'. ${ }^{4}$

Otro de los referentes críticos para el itinerario del género, Emilio Cotarelo y su Colección de loas, entremeses, bailes, jácaras y mojigangas (1911), ${ }^{5}$ además de ocuparse de los autores que cultivaron el género a partir del siglo XVI y registrar toda su pluralidad formal y argumental, establece el Viaje entretenido de Rojas Villandrando (1603) como el eje de referencia que condiciona la evolución y posterior desarrollo de la formulación dramática de la loa. ${ }^{6}$ En este sentido, a Cotarelo se debe la clasificación de las distintas modalidades de la loa, al considerar su temática y el espacio de representación, y sobre la que se basarán todos los estudios posteriores: loas sacramentales, loas de Nuestra Señora y de los Santos, loas de fiestas reales, loas en casas particulares y loas de presentación de compañías. Con posterioridad, la loa ha llamado la atención de varios investigadores, como Francisco Rico, ${ }^{7}$ Kurt Spang, ${ }^{8}$ Enrique Rull, ${ }^{9}$ Miguel Zugasti ${ }^{10}$ y Evangelina

4 Flecniakoska, La loa, 11; ver Luis Quiñones de Benavente, Jocosería, Burlas, veras, o reprensión moral y festiva de los desórdenes públicas (Madrid: García, 1645).

5 Emilio Cotarelo Mori, Colección de entremeses, loas, bailes, jácaras y mojigangas desde fines del siglo XVI a mediados del XVIII (Madrid: Bailly-Baillière, 1911), ed. facsímil, estudio preliminar e índices por José Luis Suárez y Abraham Madroñal, 2 vols (Granada: Univ. de Granada, 2000).

6 Aunque todo apunta a que, efectivamente, Rojas Villandrando tan sólo se limitó a labores de compilación: 'Contrariamente a lo que se ha sugerido a veces, Agustín de Rojas no parece haber sido ningún animador ni abrió nuevos horizontes en el arte dramático. Por un evidente error de perspectiva, el hecho de haber sido el primero en poner en letras de molde una colección de loas lo ha transformado a los ojos de muchos estudiosos en un pionero del género. Pero una lectura sin prejuicios del Viaje entretenido muestra que sus loas son experimentos retóricos que ya poco tienen que ver con las viejas funciones de un prólogo dramático' (Fausta Antonucci y Stefano Arata, La enjambre mala soy yo, el dulce panal mi obra. Veintinueve loas inéditas de Lope de Vega y otros dramaturgos del siglo XVI [Sevilla: UNED/Univ. de Sevilla/Univ. de València, 1995], 15; ver Agustín Rojas Villandrando, El viaje entretenido [Madrid: Real, 1603]).

7 Francisco Rico, 'Para el itinerario de un género menor: algunas loas de la Quinta Parte de Comedias', en Homenaje a William L. Fichter. Estudios sobre el teatro antiguo hispánico y otros ensayos, ed. A. David Kossoff y José Amor Vázquez (Madrid: Castalia, 1979), 611-21.

8 Kurt Spang, 'Aproximación a la loa sacramental y palaciega: notas estructurales', en Apuntes sobre la loa sacramental y cortesana. Loas completas de Bances Candamo, ed. Ignacio Arellano, Kurt Spang y M ${ }^{\mathrm{a}}$ Carmen Pinillos (Kassel: Reichenberger, 1994), 7-24.

9 Enrique Rull, "Apuntes para un estudio sobre la función teológica-política de la "loa" en el Siglo de Oro', en Apuntes sobre la loa sacramental y cortesana, ed. Arellano, Spang y Pinillos, 25-36.

10 Miguel Zugasti, 'Aspectos sobre la loa y la música en el umbral de la fiesta barroca', en En torno al teatro del Siglo de Oro, ed. Heraclia Castellón, Agustín de la Granja y Antonio Serrano (Almería: Instituto de Estudios Almerienses, 1995), 167-79 y 'Loa', en Diccionario de la comedia del Siglo de Oro, ed. Frank P. Casa, Luciano García Lorenzo y Germán Vega García Luengos (Madrid: Castalia, 2002), 198-99. 
Rodríguez. ${ }^{11}$ Del mismo modo, en los últimos años, también las loas de Lope de Vega,${ }^{12}$ Calderón, ${ }^{13}$ Sor Juana Inés de la Cruz,${ }^{14}$ Salazar y Torres, ${ }^{15}$ Agustín Moreto ${ }^{16}$ Antonio de Solís ${ }^{17}$ y Bances Candamo,${ }^{18}$ han sido objeto de estudio o edición por parte de la crítica.

La posición de la loa como género de cabecera de todo el espectáculo teatral supone que, en su función inaugural de la representación, su principal cometido sea el de entablar la inicial connivencia con el auditorio. De esa ubicación preliminar, en la que se establece como bisagra entre el público y la ficción escénica, deriva, sin duda, la permeabilidad que se observa en el género a lo largo de los Siglos de Oro y que necesariamente va ligada a la propia evolución del espectáculo teatral. Como antesala de la representación, la loa carece de un argumento dramático definido en términos de acción, lo cual supone su naturaleza circunstancial, así como que su morfología genérica vaya fijándose en función de los progresos del mismo espectáculo teatral que encabeza.

11 Evangelina Rodríguez Cuadros, La técnica del actor español en el Barroco. Hipótesis $y$ documentos (Madrid: Castalia, 1998).

12 Lope de Vega, Comedias de Lope de Vega. Parte I, Vol. 1: Loas, ed. Luigi Lugiani (Lleida: Milenio/Univ. Autònoma de Barcelona, 1997) y Antonucci y Arata, La enjambre mala soy yo, el dulce panal mi obra. Veintinueve loas inéditas

13 Evangelina Rodríguez Cuadros y Antonio Tordera, Calderón y la obra dramática corta (London: Tamesis, 1983); María Luisa Lobato, 'Calderón, cisne del Manzanares. Loas cortesanas y conciencia artística', en Calderón 1600-1681: Quatercentenary Studies in Memory of John E. Varey, ed., with intro., de Ann L. Mackenzie, BHS, LXXVII:1 (2000), 357-89, y Judith Farré Vidal, 'Aproximaciones al itinerario de un género teatral en el siglo XVII, a propósito de las loas palaciegas de Calderón de la Barca', Anuario Calderoniano, 2 (2009), 143-80.

14 Susana Hernández Araico, 'El código festivo renacentista barroco y las loas sacramentales de Sor Juana: Des/re/construcción del mundo europeo', en El escritor y la escena II. Actas del II Congreso de la Asociación Internacional de Teatro Español y Novohispano de los Siglos de Oro (17-20 marzo de 1993, Ciudad Juárez), ed. Ysla Campbell (Ciudad Juárez: Univ. Autónoma de Ciudad Juárez, 1994) 75-93; Sara Poot Herrera, 'Voces, ecos y caricias en las loas de Sor Juana', en Los empeños: ensayos en homenaje a Sor Juana Inés de la Cruz, ed. Sergio Fernández (México D.F.: Univ. Nacional Autónoma de México, 1995), 167-82 y Celsa Carmen García Valdés, 'Teatralidad barroca: las loas sacramentales de Sor Juana', en Sor Juana y su mundo: una mirada actual. Memorias del congreso internacional, coord. Carmen Beatriz López Portillo (México D.F.: Fondo de Cultura Económica), 207-18, por citar algunos.

15 Judith Farré Vidal, Dramaturgia y espectáculo del elogio. Loas completas de Agustín de Salazar y Torres, 2 vols (Kassel: Reichenberger, 2002).

16 Loas, entremeses y bailes de Agustín Moreto, estudio y edición de María Luisa Lobato (Kassel: Reichenberger, 2003).

17 Frédéric Serralta, 'Antonio de Solís y el teatro menor en palacio (1650-1660)', en El teatro menor en España a partir del siglo XVI: actas del coloquio celebrado en Madrid, 20-22 de mayo de 1982, ed. Luciano García Lorenzo (Madrid: CSIC, 1983), 155-72 y Fréderic Serralta, 'Una loa particular de Solís y su refundición palaciega', Criticón, 62 (1994), 111-44.

18 Apuntes sobre la loa sacramental y cortesana. Loas completas de Bances Candamo, ed. Arellano, Spang y Pinillos. 
Es así cómo la loa, en sus primeras formulaciones a lo largo del siglo XVI, se define por su carácter eminentemente recitativo. Ya sea en prosa - como resumen del argumento de la comedia que sigue-, o bien en versoerigiéndose en portavoz de una emergente conciencia profesional del oficio y sus circuitos de representación-, los recursos para la captación del interés del público más habituales en esta primera fase de evolución del género, como ya estudiara Fleckniakoska, son el saludo al público, la petición de silencio y la alabanza ${ }^{19}$ (de público, actores, ciudades ...):

La loa evoluciona al mismo tiempo que cambian el estatuto de los farsantes, el lugar de la representación y la composición del público [...] El profesionalismo sólo aparece a mediados del siglo XVI con Lope de Rueda, y corresponde a la aparición de los corrales (Madrid, 1568; Toledo, 1576; Sevilla, 1579; etc.). En este momento, la loa profana cambia de rumbo; en vez de ser la alabanza al público, y que precede al argumento, viene a resultar primero - abandonando el argumento - la alabanza de cualquier cosa y de la compañía por medio de la aplicación. ${ }^{20}$

A partir de 1580, con el establecimiento de los corrales como circuitos estables de representación, y aún bajo el formato de monólogo recitado, se observa cómo el público, ya familiarizado con el nuevo código teatral, no requiere de la función prologal de la loa para presentar la comedia en sí o resumir su intriga, sino que las necesidades apuntan más bien hacia la consolidación del espectáculo teatral en su nuevo modelo de transacción comercial. En palabras de Antonucci y Arata:

[La loa es en este momento] una curiosísima forma de contratación en la que los actores intentan definir las obligaciones y los derechos de cada una de las partes. [...] [El público es] el juez a quien las compañías se dirigen con humildad. [...] [Además] la nueva poética, basada en una producción casi industrial, necesitaba una prótasis dramática más económica y ecléctica. Un tipo de prólogo que se pudiese utilizar para diferentes comedias y en diversas situaciones. ${ }^{21}$

19 Como señala Rico, '[...] se descubrió el filón de las "loas de alabanza". Las hubo, se recordará, de todos los pelajes y calidades: "de las letras,/de plantas, de animales, de colores;/ uno alaba lo negro, otro lo blanco,/éste el silencio, la humildad el otro,/sin otras muchas de que no me acuerdo". Tales "loas de alabanza", cuyo apogeo parece coincidir con los primeros años del siglo XVII, pudieron multiplicarse fácilmente porque contaban, al margen de la escena, con el respaldo de la tradición milenaria' (Rico, 'Para el itinerario de un género menor', 613).

20 Flecniakoska, La loa, 127-28.

21 Antonucci y Arata, La enjambre mala soy yo, el dulce panal mi obra. Veintinueve loas inéditas, 11-12. 
Y buena muestra de ello son algunas loas de Lope de Vega, cuyo período de redacción puede datarse entre 1585 y 1595, donde son frecuentes, por ejemplo, las referencias a la nueva experiencia teatral en los corrales:

Entré a ver representar, por entretenerme un día, a un oficial que había llegado a cierto lugar.

Metíme entre los de a pie, y ya después de hora y media comenzóse la comedia y yo a escuchar comencé. ${ }^{22}$

También hay la alusión a los mecanismos para dar inicio a la función a partir del comentario de detalles de la propia representación. En el ejemplo que sigue, también de Lope, se trata del vestuario, puesto que la loa se concibe para acompañar a La Pastoral de Arcadia, una comedia pastoril de la que es necesario glosar en el 'prólogo' ciertos aspectos de la tradición italianizante:

El pastoral ornato que transforma, senado ilustre, hoy nuestro teatro en la forma de Arcadia famosísima, feliz asiento antiguo de pastores, no requeriría se hiciese aqueste prólogo con urbanos vestidos adornado, cual salgo agora a hacer contra el decoro y propiedad debida a la comedia.

Pero fuérzame a hacerlo el dar respuesta, o sea satisfacción, a las calumnias que acaso, entrando aquí en el vestuario, de diversos corrillos que nos miran, oí que mormuraban $[\ldots]^{23}$

Esta versatilidad de la loa, que la convierte en un género permeable a los cambios que paulatinamente se imponen con la profesionalización del entramado teatral, establece, en última instancia, que supere su condición de recitado para adoptar la forma del diálogo teatral. No se trata tan sólo de que dos o más personajes interactúen en escena, sino que con ello también pasa a plantearse la necesidad de un diseño dramatúrgico más complejo,

22 'Loa 8', en Antonucci y Arata, La enjambre mala soy yo, el dulce panal mi obra. Veintinueve loas inéditas, 83.

23 'Loa 5', en Antonucci y Arata, La enjambre mala soy yo, el dulce panal mi obra. Veintinueve loas inéditas, 67. 
acorde con el desarrollo de la comedia. Así pues, la trayectoria del género hacia su vertiente más espectacular o forma entremesada puede explicarse, dentro del circuito comercial, en el marco de la nueva experiencia teatral que supone la construcción de lugares estables para la representación, el perfeccionamiento de la técnica de los actores $\mathrm{y}$, en general, los cambios que se derivan del hecho de que el espectáculo dramático se convierta en un negocio.

En lo que atañe al ámbito palaciego, dónde la ostentación y la intencionalidad políticas caracterizan las fiestas teatrales emanadas desde la órbita del poder, las posibilidades técnicas que brinda un espacio de representación como el Coliseo del Buen Retiro, unidas a las innovaciones de los escenógrafos italianos, suponen un despliegue de medios fastuoso en el que la loa, comparsa indispensable de la comedia, se convierte en la depositaria de los principales valores panegíricos que ostenta todo el festejo cortesano. En este sentido son significativas no sólo las loas palaciegas que compone Calderón, sino también las del resto de poetas áulicos que las escriben por encargo, conocedores avezados de la retórica encomiástica que impone el género $\mathrm{y}$, no creo que casualmente, todos ligados a la protección nobiliaria o con cargos de directa designación real: Agustín de Salazar y Torres, Antonio de Solís, Francisco de Bances Candamo, Juan Vélez de Guevara...

$\mathrm{Al}$ amparo de la corte, la mayoría de dramaturgos del Siglo de Oro pueden considerarse como 'artistas pretendientes en una sociedad cortesana' que, al margen de su valía y no siempre con garantía de éxito, se verán en muchas ocasiones obligados a buscar la protección de los grandes señores para conseguir el reconocimiento social y la estabilidad económica. Tal y como señala Teresa Ferrer:

Es evidente que la transformación del hecho teatral en un fenómeno social público y estable y la profesionalización de las compañías de actores modificaron en la segunda mitad del siglo XVI las condiciones de producción y de consumo teatrales, pero aun así el mecenazgo nobiliario como aspiración a una anhelada, y difícil de conseguir, situación de estabilidad económica por parte del escritor pesó de manera determinante sobre una parte de la producción dramática del siglo XVII. [...] [E]l mecenazgo teatral de la nobleza tiene dos caras: una, más evidente, la del encargo concreto de piezas teatrales para circunstancias concretas. Otra, menos visible, que tiene que ver con el anhelo de protección por parte del artista. ${ }^{24}$

24 Teresa Ferrer Valls, 'Teatro y mecenazgo en el Siglo de Oro: Lope de Vega y el duque de Sessa', en Mecenazgo y humanidades en tiempos de Lastanosa: homenaje a la memoria de Domingo Ynduráin, ed. Aurora Egido y José Enrique Laplana (Zaragoza: Institución 'Fernando el Católico'/Instituto de Estudios Altoaragoneses, 2008), 115. Teresa Ferrer, al abordar la frustrada carrera de Lope por el patrocinio nobiliario, repasa también los casos de 
Creo que el mecenazgo efectivo o el deseo de alcanzarlo pueden ser también aspectos determinantes en el caso de la loa cortesana y su configuración como género, del mismo modo que lo fue para el drama genealógico. ${ }^{25}$ Un ejemplo paradigmático de ello puede verse al considerar la trayectoria de Antonio de Solís (1610-1686) como dramaturgo ligado a las élites nobiliarias y, posteriormente, a la corte de Felipe IV. Gracias a la exhaustiva biografía que trazó Frédéric Serralta, sabemos que entre 1636 y 1639 - probablemente en 1637 - el dramaturgo alcalaíno entró al servicio del que sería su mecenas, el séptimo conde de Oropesa,${ }^{26}$ un cargo que le valió ser nombrado secretario de Felipe IV en $1651 .{ }^{27} \mathrm{~A}$ partir de esa fecha Solís se convierte en un destacado proveedor de loas para fiestas reales. En total fueron ocho loas, que se concentran en el período que va de 1651 a $1659,{ }^{28} \mathrm{y}$ dan muestra de una trayectoria ascendente, que culmina al ser el dramaturgo elegido para el estreno en palacio del primer montaje de Antonio María Antonozzi - el escenógrafo italiano que llegó a la corte madrileña en 1658 siguiendo la estela de Cosme Lotti y Baccio del Bianco-, para conmemorar una de las circunstancias más esperadas por la monarquía, el nacimiento de Felipe Próspero, el primer hijo de Felipe IV. ${ }^{29}$

Durante esos mismos años, el dramaturgo recibió distintas prebendas: el 13 de octubre de 1653 Felipe IV le otorgó a Solís, todavía secretario sin sueldo, la cantidad de 100.000 maravedíes; ${ }^{30}$ el 6 de enero de 1654 un documento real le concedía el título de secretario real en ejercicio con la misma retribución anual que los secretarios de número; ${ }^{31}$ el 30 de abril de $1655^{32}$ fue nombrado oficial tercero de la secretaría de Estado. ${ }^{33}$ Unos años más tarde, en 1660, una carta real multiplicaba sus honorarios en concepto

25 Ver la bibliografía que propone en la primera nota de su estudio Ferrer Valls, 'Teatro y mecenazgo en el Siglo de Oro: Lope de Vega y el duque de Sessa', 113.

26 Frédéric Serralta, 'Nueva biografía de Antonio de Solís y Rivadeneyra', Criticón, 34 (1986), 51-157 (pp. 65-66).

27 Serralta, 'Nueva biografía de Antonio de Solís y Rivadeneyra', 84.

28 Loa para la comedia Darlo todo y no dar nada (1651); Loa para la comedia Las amazonas (1655); Loa para la comedia La renegada de Valladolid (1655); Loa para la comedia Eurídice y Orfeo (1655); Loa para la comedia Un bobo hace ciento (1656); Loa para la comedia Pico y Canente (1656); Loa para la comedia Triunfos de Amor y Fortuna (1658); Loa para la comedia Hipómenes y Atalanta (1659).

29 Solís escribió la comedia, Triunfos de Amor y Fortuna, y todas las piezas breves del festejo; Juan Hidalgo se ocupó de la música y la compañía de Diego Osorio fue la encargada de su puesta en escena.

30 Serralta, 'Nueva biografía de Antonio de Solís y Rivadeneyra', 86.

31 Serralta, 'Nueva biografía de Antonio de Solís y Rivadeneyra', 88.

32 Cabe señalar que 1655 es el año más prolífico de Solís en la corte, ya que, además del estreno de tres loas, son suyas las comedias que se representaron en las fiestas de Carnestolendas (Las amazonas y Eurídice y Orfeo) y, en la festividad de san Juan, de Solís es la segunda jornada de la comedia colaborada entre Monteser y Diego de Silva, La renegada de Valladolid.

33 Serralta, 'Nueva biografía de Antonio de Solís y Rivadeneyra', 89. 
JUDITH FARRÉ VIDAL

de gastos de aposento ${ }^{34} \mathrm{y}$, como cierre, el 13 de enero de 1661 fue nombrado Cronista real de Indias. ${ }^{35}$ A propósito de esa última merced, que Solís obtuvo pese a competir con un historiador consagrado como José Pellicer, resulta harto elocuente el comentario de uno de sus coetáneos, Jerónimo Mascareñas-las cursivas son nuestras:

$\mathrm{Su}$ inteligencia en las materias de la Historia es sumamente corta, y en ninguna manera es ascenso natural pasar de los chistes de las Comedias, que es su profesión, al puesto de Coronista de un tan gran Monarca ${ }^{36}$.

El comentario nos permite ver cómo, también en el circuito palaciego, resulta patente la conciencia de profesionalización en torno al teatro y cómo el oficio de dramaturgo se convierte en moneda de cambio a la hora de conseguir ascensos.

Hasta el momento, no he tomado en consideración las loas para autos sacramentales, ya que, como bien estudió Enrique Rull, su función es doble: 'propedéutica y apologética'. ${ }^{37}$ De ahí que siempre vayan ligadas a un auto concreto, por lo que su objetivo, junto al resto de piezas breves que acompañaban la celebración del Corpus, sea la exaltación de uno de los dogmas fundamentales del catolicismo, la transubstanciación eucarística. En las cuestiones de mecenazgo y profesionalización que ahora nos ocupan, a pesar de esta manifiesta ligazón argumental entre la loa sacramental y el auto, cabe apuntar, tal y como se demuestra en muchos de los documentos conservados, que se trataba de piezas de encargo bien remuneradas. ${ }^{38} \mathrm{El}$ caso de Calderón quizá sea uno de los más estudiados, por lo que traemos a colación el de Ana Caro, la autora sevillana que entre 1628 y 1645 publicó

34 Serralta, 'Nueva biografía de Antonio de Solís y Rivadeneyra', 98.

35 Serralta, 'Nueva biografía de Antonio de Solís y Rivadeneyra', 100.

36 Extraído de Jesús Antonio Cid, 'Historia, razón de estado y burocracia. Antonio de Solís contra Jerónimo Mascareñas (1662-1663)', Nueva Revista de Filología Hispánica, 47:1 (1999), 73-97 (p. 91).

37 Rull, 'Apuntes para un estudio sobre la función teológica-política de la "loa" ', 28.

38 Desde esta perspectiva, Bataillon resumía las claves en uno de los trabajos clásicos sobre la génesis del género: 'La fuerte suma pagada por la municipalidad de una ciudad a una o dos compañías teatrales para la representación del Corpus entrañaba una elevada remuneración para el poeta célebre a quien los autos habían sido encargados. Por otra parte, constituía para los directores de estas compañías una verdadera subvención que los ligaba a la ciudad al menos por el periodo que iba de Pascua al Corpus. Durante este periodo se comprometían a dar frecuentes representaciones de comedia. [.. .] Siendo tal el estatuto de las compañías bien afamadas, de aquellas para quienes escribían los poetas célebres, seguíase en ello un estímulo permanente para la producción teatral'. Ver Marcel Bataillon, 'Ensayo de explicación del auto sacramental', en Varia lección de clásicos españoles (Madrid: Gredos, 1964), 198-99. 
'obras dramáticas, relaciones de fiestas y sucesos y poemas laudatorios ${ }^{39}$ y que en el período de 1641 a 1645 recibió distintos pagos por participar en las fiestas sevillanas de Corpus. ${ }^{40}$ Lola Luna sugiere que Caro se mueve en los círculos político-cortesanos y literarios de su época, publicando en los años de valimiento del Conde Duque, ${ }^{41}$ y alternando el oficio a sueldo de escritora con el mecenazgo de los nobles. ${ }^{42}$ A pesar de que no existe constancia documentada del encargo, sí se conserva noticia de tres pagos (en 1641, 1642 y 1645) a Caro por la Loa sacramental en cuatro lenguas que se representó en el Corpus de $1639 .{ }^{43}$ Además de los recursos tópicos en torno a la alabanza del Sacramento, en la Loa destacan los elogios a la ciudad de Sevilla - una forma de captación de benevolencia muy repetida en las loas de presentación de compañía, como veremos - y, lo que es más importante, a los cabildos de la ciudad, responsables de sufragar los encargos:

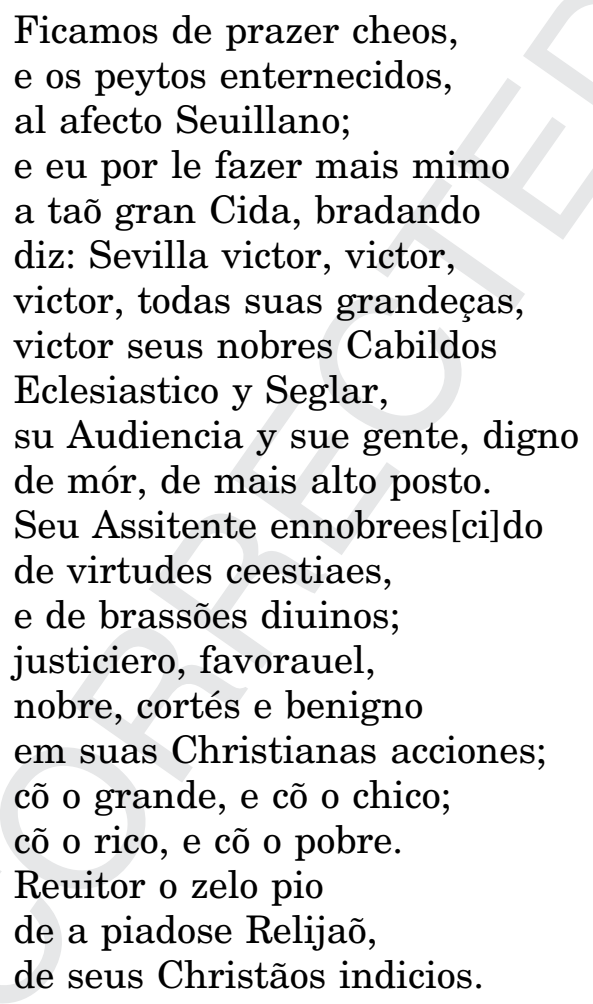

39 Lola Luna, 'Ana Caro, una escritora "de oficio" del Siglo de Oro', en An Issue of Gender: Women's Perceptions and Perceptions of Women in Hispanic Society and Literature, ed. Ann L. Mackenzie y Dorothy S. Severin, intro. de Ann L. Mackenzie, BHS, LXXII:1 (1995), 11-26 (p. 11).

40 Luna, 'Ana Caro, una escritora "de oficio" del Siglo de Oro', 15.

41 Luna, 'Ana Caro, una escritora "de oficio" del Siglo de Oro', 11.

42 Luna, 'Ana Caro, una escritora "de oficio" del Siglo de Oro', 18.

43 Luna, 'Ana Caro, una escritora "de oficio" del Siglo de Oro', 17. 
A cuyas prantas postrado pide Prado, y eu vos pido perdaõ pera nossas faltas. ${ }^{44}$

En términos generales, podría decirse que todo apunta a que el mecenazgo, unido a la cada vez más emergente profesionalización del teatro, se esgrimen como las principales razones por las que prevalece el sentido encomiástico del género. ${ }^{45} \mathrm{Y}$, de nuevo, el caso de Antonio de Solís puede esgrimirse como un claro ejemplo de ello. Concretamente, me refiero a las dos versiones que el dramaturgo escribió de una de sus loas. La primera versión (516 versos) se representó en 1643 ante los condes de Oropesa para celebrar el parto de la condesa, mientras que la segunda (346 versos) se escenificó en la corte en 1655, como antesala a La renegada de Valladolid. Las diferencias entre los dos textos son, en principio, meramente cuantitativas aunque las variantes de contenido más significativas se refieren a los fragmentos finales que condensan el elogio a sus destinatarios. Solís, plenamente consciente de los horizontes de expectativas que se imponían en cada circunstancia y espacio de representación, aprovechó hábilmente un material dramático y lo reformuló en función del encomio a sus destinatarios, cumpliendo así con la premisa básica del género. ${ }^{46}$ No creo que se tratara de una falta de ingenio

44 Cito por la edición de Francisco López Estrada, 'Una Loa al Santísimo Sacramento de Ana Caro de Mallén en cuatro lenguas', Revista de Dialectología y Tradiciones Populares, 32:1.4 (1976), 263-74 (p. 273).

45 Bances Candamo, en el cierre de su Loa para el auto del Primer duelo del mundo (1687), ofrece un interesante fragmento en el que reivindica la novedad del propio auto que, en palabras de sus editores 'debe ser entendido en conexión con las circunstancias de la escritura y representación de la loa y auto de Bances: es decir, se ha mencionado ya, la competencia que para los autos nuevos suponía la obra calderoniana, considerada cima insuperable del género. Una de las funciones, pues, de esta loa, es defender - salvando todos los respetos que Bances tiene por la obra de don Pedro - la validez de los autos nuevos' (ver Ignacio Arellano y Miguel Zugasti, 'La loa sacramental del "Primer duelo del mundo": materiales para el estudio del género en Bances Candamo', en Apuntes sobre la loa sacramental y cortesana, ed. Arellano, Spang y Pinillos, 167-87 [pp. 170-71]). De este modo el Culto, tras el elogio a la familia real y a las autoridades presentes, comenta:

se acuerden que aunque los autos

de el Fénix esclarecido

de España no hay quien iguale,

ni aun quien pueda presumirlo,

quiere Dios nuevos elogios

conforme da nuevos siglos (vv. 275-80)

46 A falta de un análisis pormenorizado entre las dos versiones, que contemple las circunstancias de representación de cada loa, véase la edición de las dos versiones que llevó a cabo Serralta, 'Una loa particular de Solís y su refundición palaciega'. 
dramático sino que, como ocurre con muchas otras prácticas propias de la generación de autores de la segunda mitad del siglo XVII — como la escritura en colaboración o la refundición-, los dramaturgos, conscientes de su oficio, rentabilizaban al máximo su quehacer dramático.

De igual manera, las loas de corral se adaptan al espacio y a las circunstancias de representación. Así, como una forma de captar la benevolencia del público, son frecuentes en las loas de presentación de compañía el elogio urbano y al auditorio, como sucede también en las loas sacramentales (así ocurría en el anterior ejemplo de Ana Caro) y palaciegas. El siguiente ejemplo que ilustra el encomio al público de la representación, aunque procede de una loa de Salazar y Torres para una fiesta a los duques de Alburquerque entre 1667 y 1669, atestigua este tipo de práctica, según uso palaciego:

$\begin{array}{ll}\text { FEBRERO } & \begin{array}{l}\text { Tengan, que falta también, } \\ \text { según uso palaciego, } \\ \text { pedir la venia a las damas. }\end{array} \\ \text { TIEMPO } & \text { ¿Qué intentas decirles, necio? } \\ \text { FEBRERO } & \text { ¿Qué he de decirles? Que son } \\ & \text { soles, planetas, luceros, } \\ & \text { pues en su hermosura están } \\ & \text { éstos, y esotros, y aquéllos. } \\ \text { DIVERSIÓN } & \text { ¿Y a las dueñas? } \\ \text { FEBRERO } & \begin{array}{l}\text { A ésas sólo } \\ \text { puede celebrar el Tiempo, }\end{array} \\ & \text { que ha días que las conoce (vv. 227-36) }\end{array}$

De ahí que, en el continuo trasvase entre corte y corral, entre materia profana y religiosa, la evolución de la loa se defina por la codificación espectacular de una serie de estrategias panegíricas que, apoyadas en la tradición ${ }^{48}$, irán desplazando paulatinamente los rasgos tipológicos del género en su estado inicial, más ligados al resumen del contenido de la comedia o a la petición de silencio de un público poco habituado a la comedia nueva.

Además, para el género específico de la loa palaciega, cuyos protagonistas suelen ser habitualmente personajes alegóricos y mitológicos, ${ }^{49}$ operan

47 Cito por la edición de Farré Vidal, Dramaturgia y espectáculo del elogio. Loas completas de Agustín de Salazar y Torres, II, 528-29.

48 Como señala Rico, "tales "loas de alabanza", cuyo apogeo parece coincidir con los primeros años del siglo XVII, pudieron multiplicarse fácilmente porque contaban, al margen de la escena, con el respaldo de una tradición milenaria' (Rico, 'Para el itinerario de un género menor', 613).

49 'el modelo constructivo gira habitualmente en torno a un debate de méritos entre una serie de personajes alegóricos (normalmente en series de dos, tres o cuatro) que pugnan por obtener el patrocinio de la celebración (Mérito, Fortuna, Aurora, Alegría, Edad, Día, Poesía, Pintura, Historia...)' (Farré Vidal, Dramaturgia y espectáculo del elogio. Loas completas de Agustín de Salazar y Torres, I, 153). 
también otros parámetros que, si retomamos ahora su definitoria naturaleza circunstancial, tienen que ver con el hecho que supone ser la pieza de apertura de todo el festejo cortesano. De este modo, como género inaugural de la fiesta, cuyo asunto debe ser la dramatización de la propia circunstancia conmemorativa y el elogio a sus destinatarios/mecenas, su efectividad pasa por buscar la complicidad del auditorio, testigo privilegiado de la espectacular puesta en escena, al que se instruye en una amena pedagogía, y según Fernando Bouza,

- en la que se mezclan el gusto y la utilidad-, pues sirve, con su etiqueta y ceremonial, para expresar una sociedad bien ordenada, al tiempo que ayuda a forjar y difundir la imagen de liberalidad y magnificencia reales que tan importante era para la construcción de la retórica del rey. ${ }^{50}$

Así pues, más aún si cabe que en la comedia, en la loa, por ausencia de argumento dramático en términos de acción, debe operar esa amena pedagogía que exige, como en la comedia mitológica, tener también presentes las exigencias y gustos del público. En este sentido ya lo apuntaba Sebastian Neumeister al estudiar los dramas mitológicos de Calderón:

En el espectáculo de la fiesta quedan cubiertos el entretenimiento y la ostentación cortesanos. La mitología clásica permite a Calderón y sus contemporáneos encontrar la forma de integrar en aquella moda de las fiestas cortesanas que, desde los trionfi de las ciudades-estado italianas, había contagiado a toda Europa, pero, al mismo tiempo, hecho de importancia primordial para la corte. La presencia de escenógrafos italianos, la imitación del stile theatrale italiano en la música, el conocimiento de la mitología y también, y no en último término, la existencia de un público entendido y culto son las condiciones previas necesarias para ello. ${ }^{51}$

En lo que atañe a las loas entremesadas representadas en los corrales de comedias, la profesionalización y las exigencias del público son también los factores que contribuyen a explicar su tipología. El carácter circunstancial del género dictamina, en este caso, que su asunto sea el mismo oficio de los actores, ya que en los corrales las circunstancias de elogio y exhibición son la propia disciplina y el oficio del comediante en un momento en el que el teatro,

50 Fernando Bouza, 'Cortes festejantes: fiesta y ocio en el cursus honorum cortesano', Manuscrits: Revista d'Història Moderna, 13 (1995), 185-206 (p. 191). Ver también Carmen Sanz Ayán, Pedagogía de reyes: el teatro palaciego en el reinado de Carlos II (Madrid: Real Academia de la Historia, 2006).

51 Sebastian Neumeister, Mito clásico y ostentación: los dramas mitológicos de Calderón (Kassel: Reichenberger, 2000), 9. 
paradójicamente, se halla inmerso de pleno en las controversias sobre su licitud moral. De la ausencia de una reflexión teórica en torno al sentido y a las funciones que el teatro desempeña como negocio y espectáculo lúdico y social se deriva que, en lo teórico, los documentos en defensa y ataque de su licitud contengan numerosas alusiones a todos los aspectos que rodean y caracterizan su entramado dramático y, en lo práctico, que las mismas obras teatrales contengan referencias metateatrales sobre el quehacer del autor y, por tanto, se hagan también eco de la polémica en torno al arte de representar comedias.

Bajo esta perspectiva, las loas de presentación de compañía, como género inaugural de la representación y de acuerdo con su función de establecer la inicial connivencia con el público, pondrán en escena algunas cuestiones referentes a la tejné del actor con el objetivo de ofrecer el lucimiento de las habilidades de los miembros que integran la compañía. ${ }^{52}$ El propósito, tal y como se anuncia en el siguiente ejemplo extraído de una loa de de Salazar y Torres para la presentación de la compañía de Agustín Manuel en Madrid (1674), es claro:

Y así pues, la compañía
en este breve diseño
se ha visto ya; los papeles
de cada uno irá diciendo
la comedia, y pues a vista
de auditorio tan supremo,
donde felizmente se unen
valor, belleza e ingenio,
en tanta hermosura y tanta
nobleza, todos a un tiempo
repitamos los aplausos
que nos acrediten cuerdos,
si antes nos hicieron locos; $(356-68)^{53}$

La captación de benevolencia como una de las funciones esenciales de la loa propicia que los actores, al reivindicar su espacio social como entretenedores, igualen en un mismo nivel de excelencia sus méritos actorales con la eminencia del público asistente a la representación. Para ello, la loa de corral suele repetir dos esquemas dramáticos: en el primero, los

52 Ver Judith Farré Vidal, 'La locura fingida de los actores como "defensa” de su tejné. El caso de algunas loas de presentación de compañías', en Locos, figurones y quijotes en el teatro del los Siglos de Oro. Actas selectas del XII Congreso de la Asociación Internacional de Teatro Español y Novohispano de los Siglos de Oro, ed. Germán Vega García Luengos y Rafael González Cañal (Almagro: Univ. de Castilla-La Mancha, 2007), 125-37.

53 Cito por la edición de Farré Vidal, Dramaturgia y espectáculo del elogio. Loas completas de Agustín de Salazar y Torres, II, 585. 
actores aparecen fingiendo que se han vuelto locos por tanta profesionalidad en el desempeño de sus papeles actorales; en el segundo, el autor se presenta soñando cómo serían los miembros ideales que formarían parte de la perfecta compañía. En ambos casos, el desenlace del artificio argumental es posible gracias al reconocimiento de la realidad de que, de hecho, la representación en las tablas ya está produciéndose - lo que más adelante analizaremos como realidad envolvente e ilusión de contemporaneidad. Así, como muestra del primer esquema argumental, sirva la desesperación de Félix Pascual en la misma loa de Salazar (1674):

apenas de la visita
salimos, cuando queriendo
hacer con mi compañía
un ensayo con intento
de ir a servir a Madrid,
todos con temas diversos
a desvariar empezaron,
y de los papeles mesmos
que han hecho en varias comedias
cada uno, según su genio
con mucha cuenta y razón,
se volvió loco; y por esto
yo sólo de tener juicio
estoy que el juicio pierdo. (vv. $49-62)^{54}$

Del mismo modo, sirven de ejemplo del segundo diseño argumental con el autor de comedias dormido, las loas de Quiñones de Benavente: Loa con que empezó en la corte Roque de Figueroa $(1627) ;{ }^{55}$ Loa que representó Antonio de Prado (1635). ${ }^{56}$

Así pues, en este fluido intercambio entre el teatro comercial y el cortesano, ${ }^{57}$ en el que se abastecen mutuamente compartiendo

54 Cito por la edición de Farré Vidal, Dramaturgia y espectáculo del elogio. Loas completas de Agustín de Salazar y Torres, II, 574.

55 Ignacio Arellano, Juan Manuel Escudero y Abraham Madroñal, Luis Quiñones de Benavente, Entremeses completos I. Jocosería (Madrid: Iberoamericana/Frankfurt am Main: Vervuert, 2001), 317-28.

56 Arellano, Escudero y Madroñal, Luis Quiñones de Benavente, Entremeses completos I. Jocosería, 229-42.

57 Tal y como señala Joan Oleza: 'A lo largo y ancho de la crítica especializada sobre el teatro de los siglos XVI y XVII ha venido dándose una unanimidad sospechosa sobre la falta, o cuando más la pobreza, de la teatralidad cortesana en España durante el Renacimiento. Es ya un tópico señalar la falta de un mecenazgo real o señorial como causa determinante y el desarrollo tardío, por ello, de una concepción espectacular específicamente cortesana, que no se produciría hasta los tiempos de Felipe III y, más plenamente, hasta la década de los veinte con la llegada de los ingenieros italianos, los Fontana, los Lotti, etc. [. . .] La consecuencia más 
dramaturgos, compañías y obras, a pesar de las distintas exigencias que requiere cada espacio de representación, surge la coyuntura oportuna en la que explicar la evolución de la loa en su formalización entremesada. Este último cambio en la tipología del género ya está plenamente asentado en la segunda mitad del siglo XVII, por lo que creo que debe ser anterior y podría localizarse a mediados de la década de 1630. En este sentido, uno de los hitos fundamentales del género hacia su vertiente entremesada puede localizarse en la Jocosería, la antología de entremeses llevada a cabo por el propio Quiñones de Benavente que, curiosamente, recoge también sus loas. Como señala Madroñal,

[e]l papel del autor toledano en este orden de cosas consistió en dar nuevo aire a este tipo de obras, imbricando en ellas la esencia del entremés, hasta constituir una especie de híbrido que se puede denominar "loa entremesada', que hace que el género se continúe en el XVII. ${ }^{58}$

La cronología de escritura y representación de las loas benaventinas abarca desde 1627 (Loa con que empezó en la corte Roque de Figueroa), 1628 (Loa segunda con que volvió Roque de Figueroa a empezar en Madrid), 1631 (Loa con que empezó Lorenzo Hurtado en Madrid la segunda vez), 1635 (Loa que representó Antonio de Prado) hasta 1636 (Loa con que empezó Tomás Fernández en la corte) ${ }^{59}$ Además, el hecho de que sea el entremés el género que dicte la poética de los géneros breves ${ }^{60}$ y que en torno a la década de 1620 , seguramente por influencia de la comedia, el verso se convierta en el cauce de expresión entremesil casi exclusivo, resultarían factores también determinantes para la loa que nos permitirían encuadrar el fenómeno hacia finales del segundo decenio del seiscientos. Debe tenerse en cuenta que si la comedia influye al entremés en la adopción del verso como cauce expresivo, el

inmediata sería la de definir la teatralidad cortesana como una derivación más del "arte nuevo", posterior en su desarrollo a éste' (Joan Oleza, 'Adonis y Venus. Una comedia cortesana del primer Lope de Vega', en Teatro y prácticas escénicas. II: La comedia, dir. Joan Oleza Simó [London: Tamesis, 1986), 309-24 [p. 309]).

58 Abraham Madroñal, 'Quiñones de Benavente y el teatro breve', en Historia del teatro español. De la Edad Media al Siglo de Oro, dir. Javier Huerta Calvo, 2 vols (Madrid: Gredos, 2003), I, 1025-68 (p. 1039).

59 Datos extraídos de Arellano, Escudero y Madroñal, Luis Quiñones de Benavente, Entremeses completos I. Jocosería, 723-25.

60 'Dentro de la fiesta teatral el entremés es la pieza básica, representada en principio entre el primero y segundo entreactos, pero pronto y bajo el modelo entremesil, fueron surgiendo otras modalidades especializadas en algunos rasgos temáticos o formales: el bailecon predominio del texto cantado sobre el recitado - , la jácara-un entremés sobre la vida airada de los jaques o valentones - y la mojiganga - traslación de la procesión carnavalesca, con su vistosidad y colorido, a los escenarios-. Todas estas formas, junto con la loa-que abría el espectáculo-, forman uno de los conjuntos de mayor riqueza de la historia del teatro no sólo español sino europeo' (Javier Huerta Calvo, 'Entremés', en Diccionario de la comedia del Siglo de Oro, ed. Casa, García Lorenzo y Vega García Luengos, 126). 
cambio repercutiría necesariamente en la loa que, aunque se venía recitando ya en verso, adoptaría entonces, por contagio entremesil, la forma del diálogo. Además, si asumimos la calificación de loa entremesada para esta forma dialogada de la loa, ello nos lleva a considerar no sólo la propia evolución del entremés como género, sino también la doble influencia de la comedia, que vendría dada por la relación de contigüidad entre la comedia como género extenso y el resto de formas breves que integran la representación, así como a partir del entremés, y, en ambos casos, son formas dramáticas dialogadas.

Por otro lado, si asumimos que dicho cambio queda plenamente establecido en la segunda mitad del siglo XVII y que, de manera específica, podría haberse producido en torno a la década de 1630, cabe ahora abordar el asunto desde la óptica que impone Calderón de la Barca como uno de los vectores fundamentales en el teatro de esa época. La primera loa de Calderón de la que tenemos constancia de representación es la que escribió para preceder a la comedia de Los tres mayores prodigios en la fiesta que tuvo lugar en la corte la noche de San Juan de $1636 .{ }^{61}$ La loa, con 542 versos, es la más extensa de su producción y el artificio dramático consiste en la puesta en escena de la síntesis argumental de la posterior comedia, ya que Jasón y Teseo, para ayudar a Hércules - desesperado por el rapto de Deyanira a manos del centauro Neso-, se ofrecen a participar en su búsqueda. Después de que Hércules acuerde distribuir sus esfuerzos - él mismo se encargará de buscar en África, mientras Teseo hará lo propio en Asia y Jasón recorrerá Europa-aparecen de nuevo los personajes alegóricos que enmarcaban la historia y subían el telón: la Noche, asistida por Pales y Flora.

La principal novedad que presenta el festejo, según los testimonios de la época, es la puesta en escena en tres escenarios distintos por parte de tres compañías diferentes que, además, representarían cada uno una jornada de la comedia: las compañías de Tomás Fernández, Prado de la Rosa y Sebastián de Prado ocuparon, respectivamente el tablado de la derecha, de la izquierda y el central. ${ }^{62}$ En esta primera loa de Calderón, en cuyo análisis ahora no nos detendremos, ${ }^{63}$ aún se observa una notoria dependencia argumental respecto a la comedia que precede - palpable en el hecho de que ambas comparten

61 Adrienne Schizzano Mandel, 'La presencia de Calderón en la loa de Los tres mayores prodigios', en Hacia Calderón. Octavo Coloquio Anglogermano. Bochum, coord. Hans Flasche (Stuttgart: Franz Steiner, 1988), 227-35 (p. 227).

62 'La función consistió en un drama compuesto adrede para ser representado por tres de las varias compañías teatrales de esta ciudad, siendo tan bueno el sujeto de la obra, y tan llamativo el lugar en que se la representó en tres distintos escenarios, y el alumbrado tan rico en novedad y atractivo que no resistiría a la tentación de enviarle a V. Excelencia una descripción más detallada, de no ser porque se precisaría una larga carta' (fragmento de la carta del embajador inglés que reproduce Schizzano a partir de Shergold en Schizzano Mandel, 'La presencia de Calderón en la loa de Los tres mayores prodigios', 227).

63 Para ello, ver Lobato, 'Calderón, cisne del Manzanares' y Farré Vidal 'Aproximaciones al itinerario de un género teatral en el siglo XVII', 157-60. 
personajes y argumento-, en una tendencia que irá disminuyendo progresivamente y que revela su posición primigenia respecto al resto de loas calderonianas.

A pesar de ello, puede decirse que la Loa para Los tres mayores prodigios exhibe los principales rasgos que distinguirán la modalidad entremesada de la loa y que, a partir de la recreación de una realidad envolvente desde una ilusión de contemporaneidad, pueden formular la traza de su tipología genérica:

La estrategia encomiástica de la loa proporciona una especial forma de dialéctica entre realidad y ficción, en la que también se integra, bajo la ilusión dramática de una realidad envolvente, al auditorio presente en el espectáculo. La loa se plantea así como una ficción dramática en la que las circunstancias que determinan la representación se convierten en el argumento espectacular que sintetiza en escena los principales valores que configuran la dramaturgia del elogio. La dicotomía entre realidad y ficción apela también a la simultaneidad del conflicto dramático para así envolver al auditorio en la participación conmemorativa de los valores panegíricos que se ostentan. La eficacia de dicho planteamiento reside en presentar la ilusión de contemporaneidad de la puesta en escena, por lo que al trazar ese argumento como un ir haciéndose a medida que va representándose, surgen de manera reiterada una serie de alusiones metateatrales acerca de la misma concepción y puesta en escena. ${ }^{64}$

Todo apunta a que, efectivamente, esos dos rasgos resultan esenciales en la evolución de la dramaturgia de la loa entremesada, tanto en el espacio de corte como en el de corral, ya que no sólo encajan en la misma inercia del género, proclive a reflejar el proceso de profesionalización del teatro, sino que también suponen que, bajo el prisma del espectáculo dramático de la segunda mitad del siglo XVII, se plantee una especial dinámica entre realidad y ficción como mecanismo fundamental para establecer la complicidad inicial con el auditorio. Esta interrelación ficción/realidad que Neumeister ya planteara para la fiesta cortesana ${ }^{65}$ creo que opera no sólo en las loas palaciegas sino en todas las variantes de la loa en la segunda mitad del siglo XVII. Se trata, en definitiva, de un proceso creativo que no es exclusivo del teatro:

La técnica pictórica, incuestionablemente barroca, de tal disposición figurativa ha sido resaltada en lo que concierne al teatro calderoniano: la implicación del receptor, la confusión entre lo contingente y lo evocado, el

64 Farré Vidal, 'Aproximaciones al itinerario de un género teatral en el siglo XVII', 152.

65 Sebastian Neumeister, 'La fiesta mitológica de Calderón en su contexto histórico', en Hacia Calderón. Tercer Coloquio Anglogermano (Londres, 1973), ed. Hans Flasche (Berlin/ New York: Walter de Gruyne, 1976), 157-70. 
valor político de la perspectiva en el arte velazqueño, etc. Emilio Orozco sugiere que la teatralización de las artes y la pintura en el Barroco se debe a la necesidad de 'ofrecer la ficción artística con la potencia expresiva de una realidad en acción, actuando como seres reales en intercomunicación psicológica y espacial con los contempladores' ${ }^{66}$

Así, la loa, como género circunstancial por definición, y maleable a la evolución del teatro y su progresiva profesionalización, funda su artificio dramático en esta especial dinámica entre realidad y ficción que, en el espacio palaciego, supone que la circunstancia conmemorativa se convierta en argumento dramático a partir de la metáfora mitológica y una espectacular puesta en escena en la que los personajes, alegóricos o mitológicos, pugnan por obtener en un debate de méritos, de acuerdo a las virtudes simbólicas que los definen, el mecenazgo festivo.

El artificio sigue vigente casi a finales del siglo XVII, con Bances Candamo. La Loa para la comedia Cómo se curan los celos y Orlando furioso (1692), por ejemplo, plantea inicialmente un desfile conmemorativo en el que, a partir de la invocación de España, participan un Genio, Babilonia, Persia, Egipto, Roma, Constantinopla y Siria, quienes acuden para implicarse en la celebración de la onomástica de Carlos II. La Noticia aparece en el tablado para vincular las letras del nombre de Carlos a otra serie de reyes ilustres de la Cristiandad, que, de alguna forma, se relacionan con España, y cuyo nombre empieza con alguna de las letras que forman el nombre de Carlos. De este modo, el panegírico adquiere una proyección simbólica atemporal que persigue celebrar al último de los Austrias como compendio de virtudes. Como desenlace, España vincula al proceso encomiástico de la celebración la elección del argumento de la comedia, supeditado a la sugerencia panegírica de la loa y, en última instancia, de toda la representación:

A este assumpto la zarzuela
y novela celebrada
de Orlando furioso y cómo
se curan los celos, halla
mi veneración, por propria
del sitio y las circunstancias
presentes (vv. $321-27)^{67}$

66 Javier Vellón Lahoz, 'El espectáculo teatral como globalidad. Dialéctica realidad/ ficción en la fiesta cortesana barroca: La fiera, el rayo y la piedra', RILCE, 9:1 (1993), 103-17 (p. 107).

67 Cito por la edición de Ignacio Arellano, 'Loa de la comedia Cómo se curan los celos y Orlando furioso', en Apuntes sobre la loa sacramental y cortesana. Loas completas de Bances Candamo, ed. Arellano, Spang y Pinillos, 253-73 (p. 272). 
En lo que respecta a las loas de presentación de compañías, la estrategia dramática recurre a convertir en argumento teatral un sueño fingido del autor o una supuesta locura de los actores que, en ambos casos, propicia la puesta en escena del desfile de los miembros de la compañía, en el que cada uno ostenta sus virtudes actorales para captar la atención del auditorio. Ese reclamo es, a la vez que defensa del oficio actoral, la estrategia para captar el interés y la benevolencia del público que ha pagado su entrada para asistir a la representación.

Así pues, la conclusión que puede extraerse es que en todos los casos operan resortes similares, puesto que la función inaugural de la loa, ya sea en el corral o en palacio, determina una doble condición periférica: confinar la realidad que precede a la puesta en escena y preceder la obra extensa que sigue. Y, en ambos espacios, resulta fundamental captar la benevolencia del público para así predisponerlo a la representación que, no lo olvidemos, ya está iniciándose con la propia puesta en escena de la loa. De ahí que la noción de realidad envolvente y el artificio de recrear una fingida simultaneidad del conflicto dramático - ese ir haciéndose a medida que va representándosesean los aspectos sobre los que abordar la tipología de la loa entremesada como género dramático. Desde esa perspectiva, tanto en el circuito comercial como en el cortesano, la misma circunstancia se convierte en el asunto dramático de la loa. Por un lado, el motivo que genera la celebración palaciega y sobre el que se ostentan los valores panegíricos del festejo; por el otro, el mismo oficio de la compañía teatral que se presenta ante el público y debe exhibir sus méritos actorales. Las mismas consecuencias pueden extrapolarse al caso de las loas sacramentales, ya que los aspectos fundamentales del auto - como el tema eucarístico, el contrarreformismo y la lucha antiherética, o la importancia de la alegoría y los mecanismos espectaculares - determinan que la adhesión del público se busque con la ejecución de la fiesta sacramental, en la que se incluyen otros géneros breves y actividades festivas litúrgicas y parateatrales. ${ }^{68}$ En ese ámbito resultan claves la función teológica-política que condensa la loa, los mecanismos espectaculares de su puesta en escena y el lucimiento de las compañías, afanosas por conseguir los exclusivos contratos para el Corpus.

68 Ignacio Arellano, 'Auto sacramental', en Diccionario de la comedia del Siglo de Oro, ed. Casa, García Lorenzo y Vega García Luengos, 22. 